\title{
DIRECT MEASUREMENT OF REACTION FORCES DURING FAST DYNAMIC LOADING
}

\author{
Jan Falta*, Marcel Adorna, Tomáš Fíla, Petr Zlámal \\ Czech Technical University in Prague, Faculty of Transportation Sciences, Department of Mechanics and \\ Materials, Konviktská 20, 12000 Prague 1, Czech Republic \\ * corresponding author: falta@fd.cvut.cz
}

\begin{abstract}
The presented paper is focused on embedding of the serially manufactured piezo-electric impact loadcell into Open Hopkinson Pressure Bar (OHPB) and it's modifications for a direct force measurement during dynamic loading. Conventionally, during the SHPB test dynamic force equilibrium is investigated by a comparison of the transmitted signal wave and the difference between the incident, reflected and transmitted signals measured by strain gauges [1. However, in the experiments with specimens with low mechanical impedance, a major portion of the incident wave is reflected back on the interface between the bar and the specimen. Comparison between two-large amplitude incident and reflected pulse and a small-amplitude transmitted pulse can be influenced by large error and resulting force equilibrium can be inaccurate. Therefore, a piezo-electric quartz impact force transducer was used to directly measure the axial forces in the vicinity of the specimen end surfaces.
\end{abstract}

KEYWORDS: Hopkinson bar, instrumentation, strain-gauge measurement, piezo-electric loadcell.

\section{INTRODUCTION}

Over the past decades, dynamic mechanical testing become widely used method for determination of properties of modern materials (e. g. metal foams, laser sintered structures). Reliable recording of the dynamic response of the material during impact testing is therefore essential for obtaining required material properties at high strain rates. The strain gauges are one of the most commonly used sensors in dynamic testing devices (e. g. Split Hopkinson Pressure Bar, Charpy impact test, Drop tower). Another way to measure reaction forces can be use of piezo-electric loadcell. In order to obtain reliable data, these sensors must be properly calibrated in a expected range of measured forces starting at $2 \mathrm{kN}$ up to $20 \mathrm{kN}$. According to Fujii, et. al., 2003 [2], there are three methods for calibrating dynamic force transducers. Calibrating against oscillation forces, impact force or against a step force. However, all of these methods require expensive equipment and a calibrated reference sensor. This paper presents embedding of the serial manufactured piezoelectric impact load cell into OHPB (Open Hopkinson Pressure Bar) and its calibration using two pairs of strain gauges as reference sensors. Calibration of the strain gauges can be done using static loading procedure without much difficulty was demonstrated in the previous research [3].

\section{Testing Setup}

OHPB, modification of standard SHPB apparatus was used for calibration of the force transducer. In this case incident bar was guided by a linear guidance system and was instrumented with strain gauges (see Figure 1). The incident bar with length of $1600 \mathrm{~mm}$ and diameter of $20 \mathrm{~mm}$ made from high strength aluminum alloy (EN-AW-7075) was used. The impact bar was fitted with foil strain gauges 3/120 LY61 (HBM, Germany) with active length $3 \mathrm{~mm}$ wired in the Wheatstone half-bridge arrangement at a distance of $200 \mathrm{~mm}$ from the face of the bar. The nominal resistance deviation of the strain gauge according to manufacturer is $1 \%$. The transmission part consists of two bars of the same material with lengths of $230 \mathrm{~mm}$ (first bar) and $1470 \mathrm{~mm}$ (second bar) between which a load cell is mounted. These rods are supported by a low friction polymer housings (drylin series, IGUS, Germany) and instrumented using same strain gauges as on the incident bar. Calibration of the strain gauges was carried out by gradual increasing of static load by $100 \mathrm{~N}$ step. Both strain gauges are located at a distance of $60 \mathrm{~mm}$ from the load cell. Since the load cell is not designed to measure tensile forces, and in the standard configuration the tensile wave is reflected at the free end of the transmission bar, a third rod was added to avoid the tensile wave from returning to the load cell and preventing cause possible damage. Instrumentation of the load cell and strain gauges can be seen in Figure 2 .

\section{Piezoelectric force TRANSDUCER}

Most of the dynamic force transducers are based on piezoelectric crystals. Principle of piezoelectric crystals stands on the generation of electric charge due to compression by the external force [4. Thus, the generated electric charge is converted as a small change in voltage at the output and readout by a corresponding measuring device. The main reason for using of piezo- 


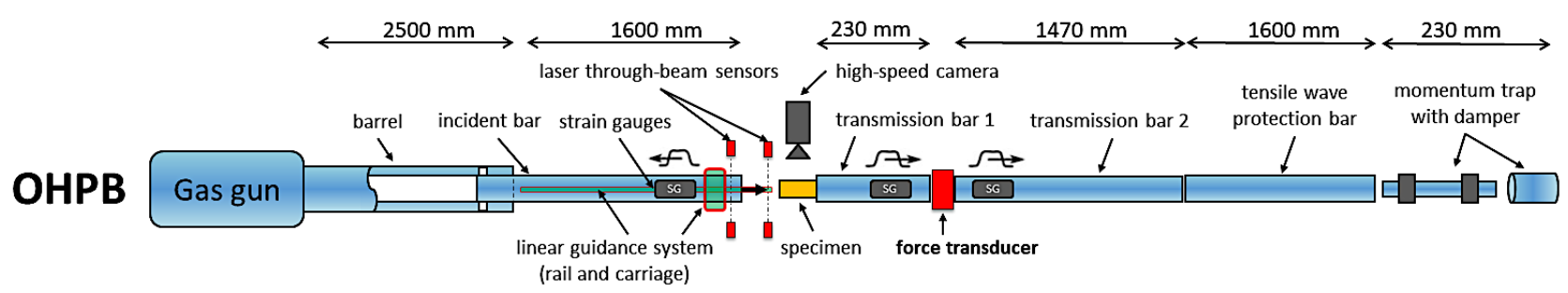

Figure 1. OHPB setup scheme

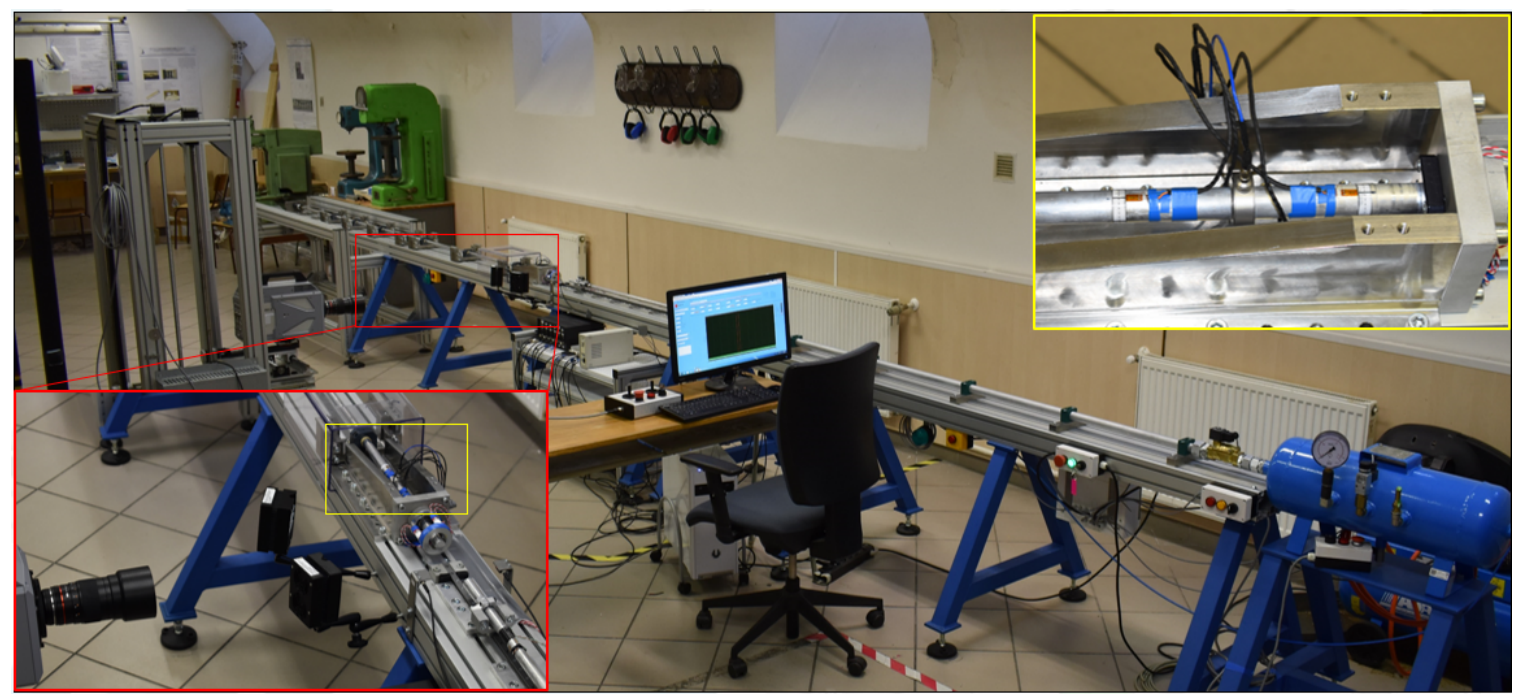

FigURE 2. Experimental setup overview

electric crystals for dynamic loading measurements is their high natural frequency limit (commonly in order of $100 \mathrm{kHz}$ ) and quasi-linear behavior over a wide amplitude range (PCB Piezotronics, 2012) [5]. However, these sensors are unable to measure static and quasistatic loads or tensile load without prestressing. In this paper, a quartz crystal force sensor type 200C20 (PCB Piezotronics, Inc.USA) was used in calibration experiments. This sensor is designed to measure compression forces in a range starting at units of $\mathrm{N}$ up to $88.96 \mathrm{kN}$ with sensitivity of $56.2 \mathrm{mV} / \mathrm{kN}$ and upper frequency limit of $40 \mathrm{kHz}$ [6]. This type of sensors in general have quasi-linear output above approx. $20 \%$ of Full Scale Output (FSO) (see Figure 3).

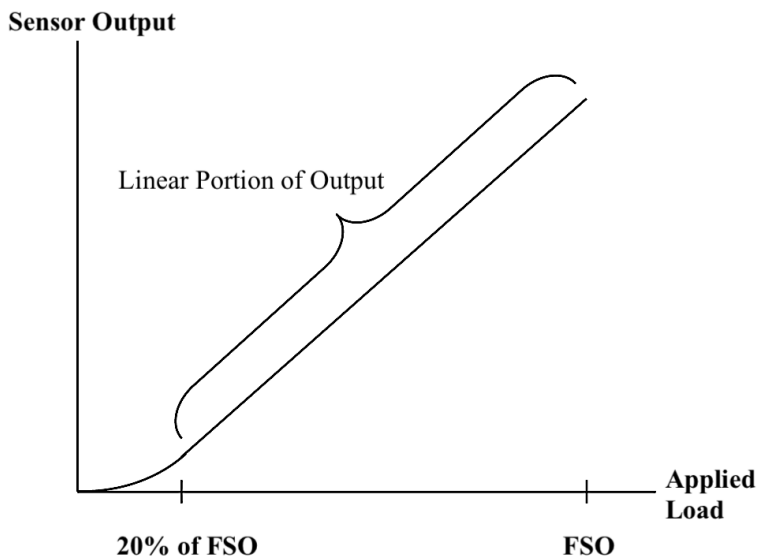

Figure 3. Output - applied force [5]
If the measured forces are lower than this threshold, it is necessary to preload the sensor (quartz) to shift into the linear region. In our case the dimension of thread in the load cell and both bars is $1 / 4^{\prime \prime}-28$ with tensile strength approx. $10 \mathrm{kN}$ for steel thread and bolt. The $20 \%$ load threshold for instrumented load cell is $17.8 \mathrm{kN}$. Preload above this threshold would require the use of a strength screw of class 10.9 . or 12.9 which significantly exceeds the strength capacity of the alluminium rod. Therefore, it was not possible to applied enough preload force to reach linear output dependency.

\subsection{LOAD CELL CALIBRATION}

Force sensor was mounted between two bars with steel bolt using a threaded steel bolt (see Figure 4 . Two strain gauges were instrumented on adjacent bars in the distance of $60 \mathrm{~mm}$ (see Figure 1). For the load cell

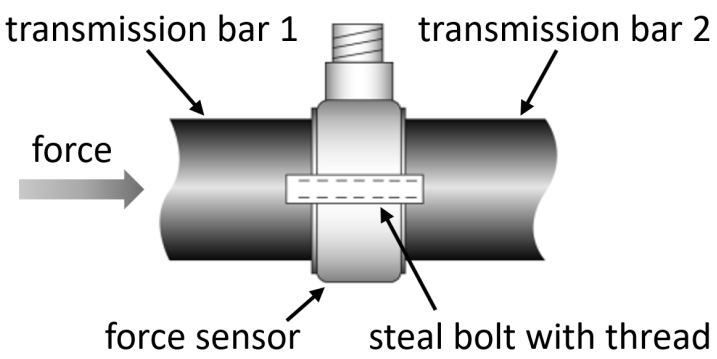

Figure 4. Quartz force sensor arrangement 6 
calibration, 38 void tests (direct impact of the incident bar without sample) were performed in load range of $2 \mathrm{kN}-28 \mathrm{kN}$. The signal measured by the load cell was converted to the unit of force using sensitivity constant $(17.241 \mathrm{~N} / \mathrm{mV})$ given by the manufacturer. The force signal measured by the load cell was compared with signals from the strain gauges and a growing deviation was observed with decreasing applied force. Selected waveforms of the measured signals for three different loads of $2 \mathrm{kN}, 8 \mathrm{kN}$ and $15 \mathrm{kN}$ are shown in Figures 5-7. The correction coefficient was determined as the ratio between the mean value of forces measured by strain gauges and average force measured by the load cell from the plateau area of the deformation pulse.

It can be seen that the shape of the load cell signal corresponds with the strain gauges signal and the difference between the load cell and strain-gauge is decreasing with the applied force. The overall signal-tonoise ratio with used instrumentation is significantly lower for load cell signal.

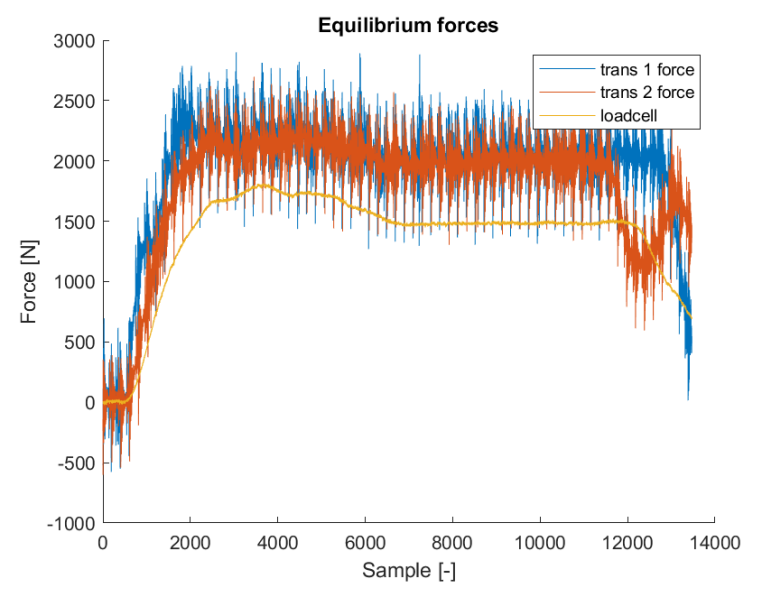

Figure 5. Calibration experiment at low impact force (approx. $2 \mathrm{kN}$ ) with deviation corresponding to Force ratio coefficient of 1.315

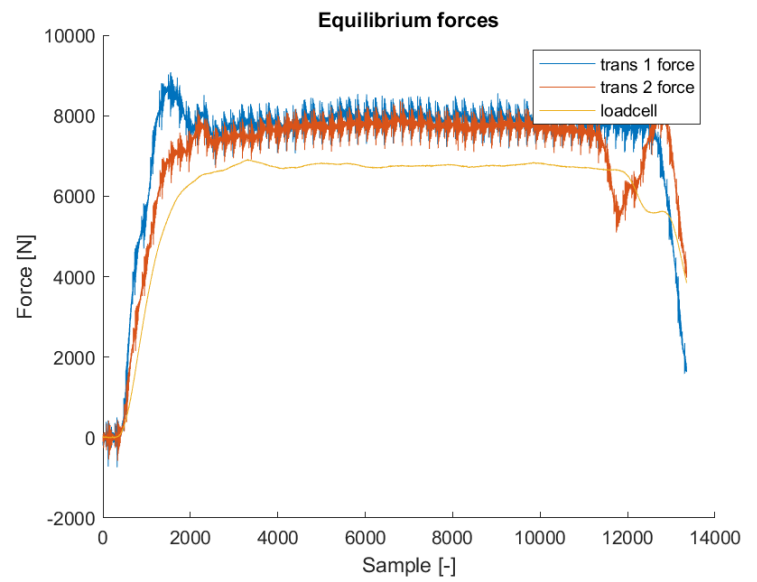

FiguRE 6. Calibration experiment at low impact force (approx. $8 \mathrm{kN}$ ) with deviation corresponding to Force ratio coefficient of 1.143

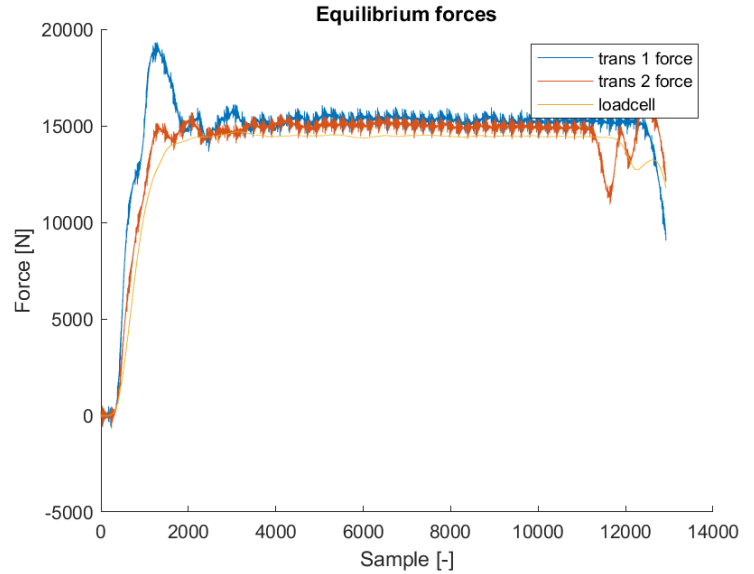

Figure 7. Calibration experiment at low impact force (approx. $15 \mathrm{kN}$ ) with deviation corresponding to Force ratio coefficient of 1.048

In recommended installation, shown in Figure 4 , the load cell is preloaded with Beryllium-Copper (Be- $\mathrm{Cu}$ ) thread stud which is supplied by the manufacturer. This configuration allows a portion of the force to pass through the stud. According to the manufacturer, the $\mathrm{Be}-\mathrm{Cu}$ stud may cause deviation of $5 \%$ of the measured force. In our case, steel stud was used which could cause a further increase in deviation. The total deviation is also dependent on the applied preload force. If this force is less than $20 \%$ FSO, calibration of the load cell is also necessary.

\section{Results}

All measured data are plotted in Figure 8 as load cell transducer non-linear output dependency on applied force. Because of low level of applied preload force, the strong non-linearity was observed throughout the measured range. As shown in Figure 3 under $20 \%$ of FSO the load cell has a strong nonlinear characteristics. In that case it is necessary to set the correction coefficient depending on the applied force to obtain the correct value.

One possibility is to divide the nonlinear region into sufficiently small sections and linearize them to obtain the corresponding conversion factor for each of them based on the strain gauge signal. Another possibility is to define the function approximating the non-linearity of the measured forces for the required measuring area to determine the corresponding value of the conversion coefficient according to this function.

The load cell calibration is strongly dependent on the required range of measured forces with respect to the total measuring range of the load cell and the maximum technically achievable preload force. The situation can be divided into two basic cases:

\section{Preload force itself or with applied load is more than $20 \%$ of FSO}

Output has quasi-linear dependency. One correction coefficient is used. The measurement can be strongly influenced by power transmission through the screw. 


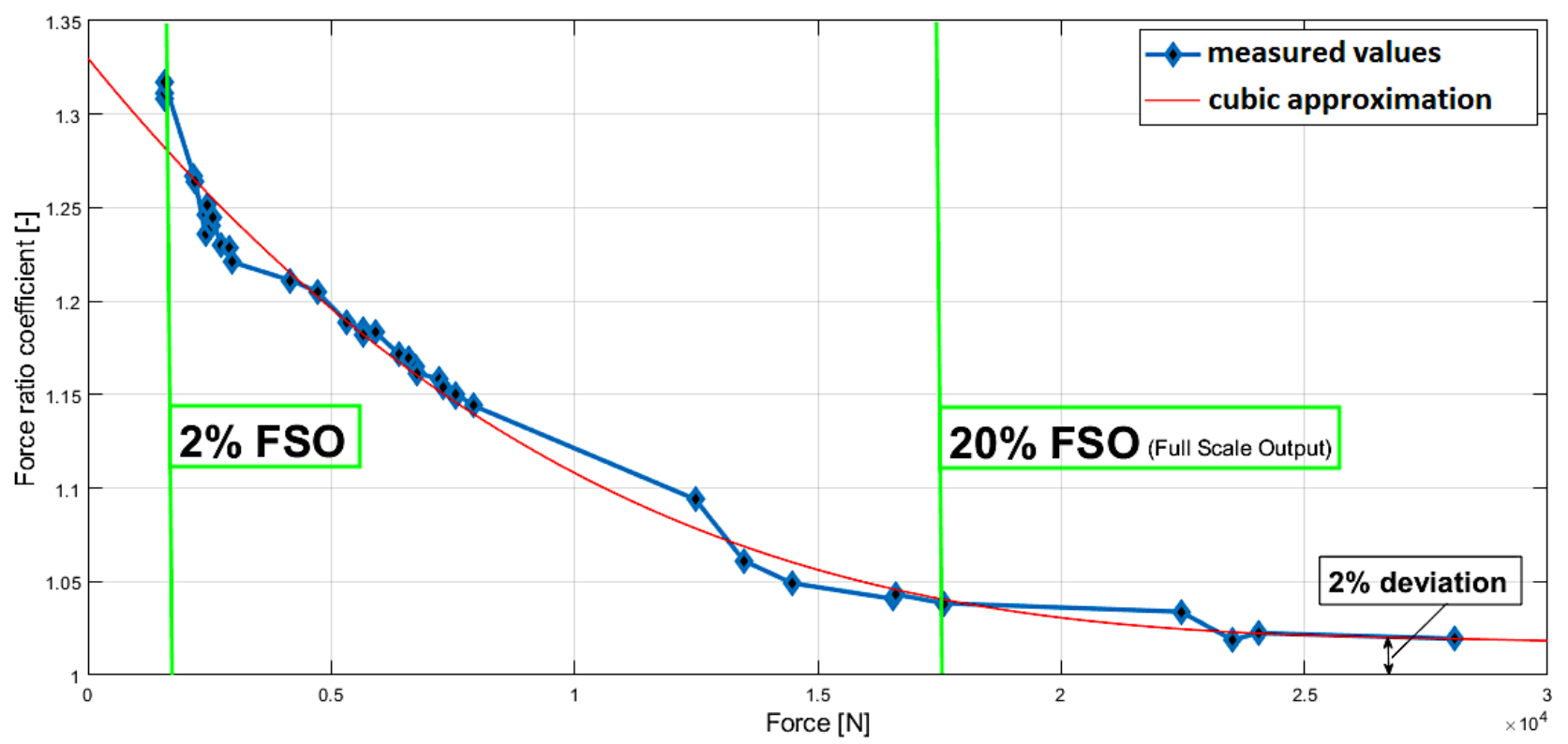

FiguRE 8. Measured nonlinearity of the force transducer

\section{Preload force with applied load is less than $20 \%$ of FSO}

Output has non-linear dependency. It is necessary to perform calibration over the entire measured range and to determine the discrete or continuous correction coefficients. The effect of the preload bolt is considerably lower.

\section{CONClusion}

The performed experiments show that it is possible to use the OHPB for calibration and subsequent measurement with a piezoelectric force transducer. The load cell accuracy is limited by the type of strain gauges used to calibrate it.Therefore, it is not possible to reach higher precision with load cell than with strain gauges. However, the reliability of strain gauges and their service life is strongly influenced by the process and quality of the instrumentation, causing a number of failures especially in high strain-rate tests. In contrast, the load cell exhibits high reliability and does not suffer significantly due to cyclic loading. The load cell signal quality is also substantially higher compared to the strain gauges, and in some measurements it can be critical for a reliable evaluation of the experiment. The main objective is to choose a suitable load cell with respect to the measured range of deformation forces. After selecting a suitable working range of the load cell, it is necessary to ensure that the maximum permissible pressure force will not be exceeded and the reflected tensile deformation waves are eliminated to protect the load cell from possible damage. These requirements can be very difficult to achieve with devices operating on the SHPB principle. If a suitable load cell is selected, the quasi-linearity of the output values can be achieved even for measurements of small forces. In cases where it is not possible to use suitable load cell due to the price or installation (max. diameter of preload stud), the methods proposed in this work can be used.

\section{ACKNOWLEDGEMENTS}

The research was supported by the Czech Science Foundation (project no. 19-23675S) and the internal grants of the Czech Technical University in Prague (project no. SGS18/153/OHK2/2T/16 and SGS18/154/OHK2/2T/16). All the financial support is gratefully acknowledged.

\section{REFERENCES}

[1] T. Fila, P. Zlamal, J. Falta, et al. Testing of auxetic materials using hopkinson bar and digital image correlation. EPJ Web of Conferences 183:02045, 2018. DOI:10.1051/epjconf/201818302045.

[2] Y. Fujii. Proposal for a step response evaluation method for force transducers. Measurement Science and Technology 14:1741, 2003.

DOI:10.1088/0957-0233/14/10/301.

[3] J. Falta, T. Fila, M. Adorna, P. Zlamal. Optimization of hopkinson bar instrumentation for cellular and low impedance materials. Engieneering Mechanics, 25th International conference, Svratka, Czech Republic pp. 97-101, 2019.

[4] D. Van Nuffel, J. Peirs, I. De Baere, et al. Calibration of dynamic piezoelectric force transducers using the Hopkinson bar technique. 2012.

[5] B. Metz. Optimizing 3-component force sensor installation for satellite force limited vibration testing. 28th Space Simulation Conference - Extreme Environments: Pushing the Boundaries 2014.

[6] P. Piezotronics. Technical sheet of dynamic force transducer of type 200c20, 2019. http://www.pcb.com/products . aspx?m=200c20. 